\title{
Optimization of antifungal activity by Bacillus subtilis isolate CCASU 2021-4 using Response Surface Methodology
}

\author{
Ghadir S. El-Housseiny ${ }^{\mathrm{a}}$, Geena N. Nagy ${ }^{\mathrm{b}}$, Zeina T. Ghobashi ${ }^{\mathrm{b}}$, Rawan M. Mostafa ${ }^{\mathrm{b}}$, Israa M. Abd-Allah ${ }^{\mathrm{a}}$, \\ Sarra E. Saleh ${ }^{\mathrm{a}^{*}}$ \\ ${ }^{a}$ Department of Microbiology and Immunology, Faculty of Pharmacy, Ain Shams University, Cairo 11566, Egypt \\ ${ }^{\mathrm{b}}$ Faculty of Pharmacy, Ain Shams University, Cairo 11566, Egypt
}

\begin{abstract}
Fungal infections represent an enormous load on the public especially with the development of resistance to the most currently used antifungal drugs in practice. In the present work, a bacterial isolate coded A3 was recovered from soil and was shown to express antagonistic activity against Candida (C.) albicans ATCC 10231. This isolate was identified as Bacillus (B.) subtilis subsp. spizizenii isolate CCASU 2021-4 using 16S ribosomal RNA sequencing. D-optimal design from response surface methodology (RSM) was used to optimize the environmental variables affecting the antifungal activity of the respective isolate. The optimum conditions were a temperature of 30 ${ }^{\circ} \mathrm{C}$, a pH of 8 , and an inoculum size of $5 \times 10^{7} \mathrm{cfu} / \mathrm{mL}$, resulting in an enhancement in the antifungal activity by 1.2 fold. This is the first report, to the best of our knowledge, on an antifungal activity from B. subtilis subsp. spizizenii culture broth against human fungal pathogens along with its optimization through RSM.
\end{abstract}

Keywords: antifungal; optimization; D optimal design; Bacillus subtilis; response surface methodology.

*Correspondence | Sarra E. Saleh; Department of Microbiology and Immunology, Faculty of Pharmacy, Ain Shams University, Cairo 11566, Egypt. Email: sarradeif@pharma.asu.edu.eg

Citation | El-Housseiny GS, Nagy GN, Ghobashi ZT, Mostafa RM, Abd-Allah IM, Saleh SE, 2021. Optimization of antifungal activity by

Bacillus subtilis isolate CCASU 2021-4 using Response Surface Methodology. Arch Pharm Sci ASU 5(1): 171-183

DOI: $10.21608 /$ aps. 2021.80383 .1063

Print ISSN: 2356-8380. Online ISSN: 2356-8399.

Received 12 June 2021. Accepted 16 June 2021.

Copyright: ${ }^{\oplus} 2021$ El-Housseiny et al. This is an open-access article licensed under a Creative Commons Attribution 4.0 International License (CC BY 4.0), which permits unrestricted use, distribution, and reproduction in any medium, provided the original author(s) and source are credited.

Published by: Ain Shams University, Faculty of Pharmacy

\section{INTRODUCTION}

Fungal diseases have greatly risen with the increase in patients with malignancies, immunocompromised patients, as well as those suffering severe illnesses. Candida species are responsible for a lot of these infections [1, 2]. About $20 \%$ of intensive care unit infections were attributed to invasive candidiasis [3] while opportunistic infection by $C$. albicans represents about $95 \%$ of oropharyngeal candidiasis in human immunodeficiency virus (HIV)-positive patients [4]. The great increase in the appearance of drug-resistant Candida isolates represents a serious threat to humans $[5,6]$. Recently, pharmaceutical practices consider combating fungi/yeast as a challenge facing common drugs owing to the adverse effects of these drugs as well as regimes of antifungals that are becoming inefficient over time [7]. Therefore, it is a must to discover new antifungal drugs for the treatment of fungal infections in humans.

The microbial communities in soil confer a diverse and highly complicated system [8]. There are complex interactions between bacteria and 
fungi in any environment which supports the development of mixed bacterial and fungal flora. Bacterial secondary metabolites which have antifungal activity donate bacteria an ecological advantage in these environments. A variety of in vitro methods have been used to confirm this activity and represent the basis for the improvement of numerous drugs with antifungal activity [9]. For example, amphotericin B was obtained from Streptomyces nodosus by purification of the metabolites [10]. Likewise, nystatin was obtained from Streptomyces noursei as well as pyrrolnitrin which is obtained from Pseudomonas pyrrocinia [11]. Moreover, alterations of these bacterial secondary metabolites chemically aided in the development of semi-synthetic antifungals with upgraded activity [12].

In addition to Pseudomonas and Streptomyces, Bacillus sp. has also proved to be efficient against fungal pathogens. B. subtilis has been reported to produce more than 70 different antibiotics [13]. According to several authors, secondary metabolites with antifungal activity against phytopathogenic microorganisms are produced by certain species of Bacillus. Some authors have suggested that the use of some of those species, or their metabolites, may be an alternative to the protection of plants chemically [14]. endospore-forming Bacillus sp. have properties that make them suitable for use as biocontrol agents, such as good stress resistance and producing fungal toxic compounds of low molecular weight. For example, subtilin, a peptide antibiotic, has been isolated from $B$. subtilis ATCC 6633 [15].

Therefore, our study aimed to screen soil bacterial isolates for a promising antifungal producer in addition to optimization of this antifungal activity using RSM.

\section{MATERIALS AND METHODS}

\subsection{Collection of soil samples, recovery, and maintenance of isolates}

Ten soil samples were randomly obtained from different areas in Cairo taken from a depth of $10-20 \mathrm{~cm}$. A gram of each sample was transferred into $100 \mathrm{~mL}$ saline, agitated for 30 min then $100 \mu \mathrm{L}$ of the supernatant was spread on trypticase soy agar (TSA) and incubated at 37 ${ }^{\circ} \mathrm{C}$ for 2 days. The isolated colonies were then selected, grown on the same culture media, and preserved at $4{ }^{\circ} \mathrm{C}$. After screening, the selected isolate which showed maximum antifungal activity was maintained in Trypticase soy broth (TSB) (Lab M, Topley house, England) with $20 \%$ glycerol at $-80{ }^{\circ} \mathrm{C}$.

\subsection{Screening of the obtained isolates for antifungal activity}

The activity of the recovered isolates against standard strain C. albicans ATCC 10231 was tested using cross streak assay using Sabouraud`s dextrose agar (SDA) plates and incubated at 30 ${ }^{\circ} \mathrm{C}$ for $24 \mathrm{~h}$ to allow the production of metabolite(s) [16]. Subsequently, C. albicans was inoculated perpendicular to the isolates' growth. Any inhibition zone (IZ) between the tested isolates and $C$. albicans ATCC 10231 after incubation at $28{ }^{\circ} \mathrm{C}$ for $48 \mathrm{~h}[\mathbf{1 7}, \mathbf{1 8}]$ was recorded. The isolates showing inhibition zones were selected for further studies.

The agar well diffusion technique was used to confirm the antifungal production [19]. After 2 days of incubation, culture broths of the selected isolates in TSB were centrifuged and filter sterilized using $0.22 \mu \mathrm{m}$ membrane filters (Ministart ${ }^{\circledR}$ syringe filter) to get cell-free supernatants (CFS). The CFS was tested against a seeded culture of $C$. albicans ATCC 10231 (final concentration equivalent to 0.5 McFarland standards). The resultant IZs were measured after incubation at $28{ }^{\circ} \mathrm{C}$ for $24 \mathrm{~h} \mathrm{[20]}$. The isolate 
which showed the largest IZ was chosen for subsequent experiments.

\subsection{Identification of the selected isolate}

The first microscopical examination was done using the Gram stain technique. For DNA sequencing of $16 \mathrm{~S}$ ribosomal RNA, isolate A3 was grown on nutrient agar and incubated at 30 ${ }^{\circ} \mathrm{C}$ for $20 \mathrm{~h}$. After DNA extraction and PCR amplification, DNA sequencing of the 16S ribosomal RNA gene was done at GATC Company, Germany. The sequence assembly and DNA analysis were carried out using the Staden package program (http://staden.sourceforge.net/) and the final sequence was aligned and blasted in the GenBank database using BLAST (Basic Local Alignment Search Tool) (http://blast.ncbi.nlm.nih.gov/Blast.cgi) [21]. The $16 \mathrm{~S}$ ribosomal RNA sequence was put in the Culture Collection Ain Shams University (strain number, CCASU 2021-4) which belongs to the World Data Centre for Microorganisms (WDCM). (http://www.wdem.org/).

\subsection{Antifungal metabolite(s) production}

Seed culture was prepared by inoculating isolate A3 into $50 \mathrm{~mL}$ TSB and incubating for $15-18 \mathrm{~h}$ at $200 \mathrm{rpm}$ and $30{ }^{\circ} \mathrm{C}$. About $1 \mathrm{~mL}$ from this culture was then centrifuged then the obtained cells, after washing with normal saline, were resuspended in the production media to obtain a final count of $1 \times 10^{7} \mathrm{cfu} / \mathrm{mL}$. The medium used for production was prepared according to Sayed et al. [22] and Singh et al [23] and consisted of : $5 \mathrm{~g} / \mathrm{L}$ starch, $6 \mathrm{~g} / \mathrm{L}$ $\mathrm{Na}_{2} \mathrm{HPO} 4,3 \mathrm{~g} / \mathrm{L} \mathrm{K}{ }_{2} \mathrm{HPO} 4,0.2 \mathrm{~g} / \mathrm{L} \mathrm{CaCl} 2,0.5 \mathrm{~g} / \mathrm{L}$ $\mathrm{NaCl}, 5 \mathrm{~g} / \mathrm{L} \quad \mathrm{NH}_{4} \mathrm{Cl}, \quad 0.12 \mathrm{~g} / \mathrm{L} \quad \mathrm{MgSO}_{4}$ and distilled $\mathrm{H}_{2} \mathrm{O}$ to $1 \mathrm{~L}$. The $\mathrm{pH}$ was adjusted using $\mathrm{KOH}$ pellets to $\mathrm{pH}$ 7. From the seed culture, one milliliter was used to inoculate each $30 \mathrm{~mL}$ of the medium of then incubated at $200 \mathrm{rpm}$ and $28^{\circ} \mathrm{C}$.

\subsection{Estimation of the antifungal concentration}

The equation of a standard calibration curve of standard terbinafine (Lamisil@) designed in our previous study [22] was used to calculate antifungal concentration as follows:

$\mathrm{Y}=0.0169 \mathrm{X}+5.0022$,

Where $\mathrm{X}$ is the concentration of the antifungal metabolite $(\mathrm{s})(\mu \mathrm{g} / \mathrm{mL})$ and $\mathrm{Y}$ is IZ diameter (mm).

\subsection{Diverse variables influencing antifungal production}

\subsubsection{Antifungal production time course}

To determine the required time for greatest antifungal production, we prepared seven flasks $(250 \mathrm{~mL})$ as mentioned above and incubated them at $28{ }^{\circ} \mathrm{C}$ and $200 \mathrm{rpm}$. A single flask was sampled daily for 5 days to obtain the CFS. Briefly, $1 \mathrm{ml}$ of the culture was centrifuged and the filter-sterilized CFS (200 $\mu \mathrm{L} /$ well) was evaluated by the agar well diffusion technique. After $24 \mathrm{~h}$ of incubation at $28{ }^{\circ} \mathrm{C}$, IZ against $C$. albicans ATCC 10231 was measured.

\subsubsection{RSM for Optimization of antifungal production}

RSM, specifically D-optimal design was used to optimize 3 variables including temperature (A), $\mathrm{pH}(\mathrm{B})$, and inoculum size (C). Three levels were chosen for each factor, as illustrated in Table 1 and a sum of 13 runs was constructed (Table 2). At the end of each experiment, the culture was centrifuged then the antifungal activity of the CFS was detected. A single response value, IZ diameter $(\mathrm{mm})$, was obtained after 3 days of incubation. An equation, including all significant terms, was obtained from the program. Design Expert ${ }^{\circledR}$ v. 7.0 (Design Expert $^{\circledR}$ Software, Stat-Ease Inc., MN, USA) was used to perform the design of experiments. 


\subsubsection{Experimental Validation of RSM results}

The optimal environmental conditions (which were attempted experimentally) were obtained using the numerical optimization function in the software. Production using these conditions was then compared to the production using initial conditions.

Table 1. Temperature, $\mathrm{pH}$ and inoculum size as test factors and their used levels for RSM

\begin{tabular}{lccc}
\hline Variable & & & Level \\
& $\mathbf{- 1}$ & $\mathbf{0}$ & $\mathbf{+ 1}$ \\
\hline Temperature $\left({ }^{\circ} \mathrm{C}\right)$ & 23 & 30 & 37 \\
$\mathrm{pH}$ & 6 & 7 & 8 \\
Inoculum size $\left(\mathrm{x} 10^{6}\right)$ & 1 & 50.5 & 100 \\
\hline
\end{tabular}

Table 2. D-optimal design runs for $B$. subtilis isolate $\mathbf{A 3}$

\begin{tabular}{|c|c|c|c|c|}
\hline Run no & Temperature $\left({ }^{\circ} \mathbf{C}\right)$ & $\mathbf{p H}$ & $\begin{array}{l}\text { Inoculum Size } \\
\left(\mathbf{x 1 0}^{6} \mathrm{cfu} / \mathrm{mL}\right)\end{array}$ & $\begin{array}{l}\text { Observed Inhibition } \\
\text { zone }(\mathbf{m m})\end{array}$ \\
\hline 1 & 23.00 & 8.00 & 1 & 0 \\
\hline 2 & 30.00 & 7.00 & 50.5 & 25 \\
\hline 3 & 23.00 & 7.00 & 50.5 & 26 \\
\hline 4 & 30.00 & 6.00 & 1 & 0 \\
\hline 5 & 23.00 & 8.00 & 100 & 23 \\
\hline 6 & 30.00 & 8.00 & 50.5 & 27 \\
\hline 7 & 30.00 & 7.00 & 100 & 0 \\
\hline 8 & 37.00 & 8.00 & 100 & 0 \\
\hline 9 & 37.00 & 6.00 & 100 & 0 \\
\hline 10 & 23.00 & 6.00 & 100 & 14 \\
\hline 11 & 37.00 & 7.00 & 1 & 0 \\
\hline 12 & 37.00 & 7.00 & 50.5 & 23 \\
\hline 13 & 37.00 & 7.00 & 1 & 0 \\
\hline
\end{tabular}




\subsection{Statistical and graphical analysis}

The values recorded for all experiments were the average of 3 experiments whereas the data standard deviation was indicated by error bars. Design Expert v. 7.0 was used to obtain the design of experiments, response surfaces, model diagnostic plots, and ANOVA.

\section{RESULTS}

\subsection{Recovery of the bacterial isolates and screening for antifungal activity}

A sum of 54 bacterial isolates was obtained from the 10 gathered soil samples. Only, 4 (coded A2, A3, D5, and G4) out of 54 isolates (7.4\%) displayed IZ against $C$. albicans ATCC 10231 suggesting their antifungal activities. The antifungal activities of these 4 isolates were confirmed using the agar well diffusion method. Isolate A3 showed the largest inhibition zone of $20 \mathrm{~mm}$ when compared to the rest and therefore, it was chosen for subsequent experiments (Fig. 1).

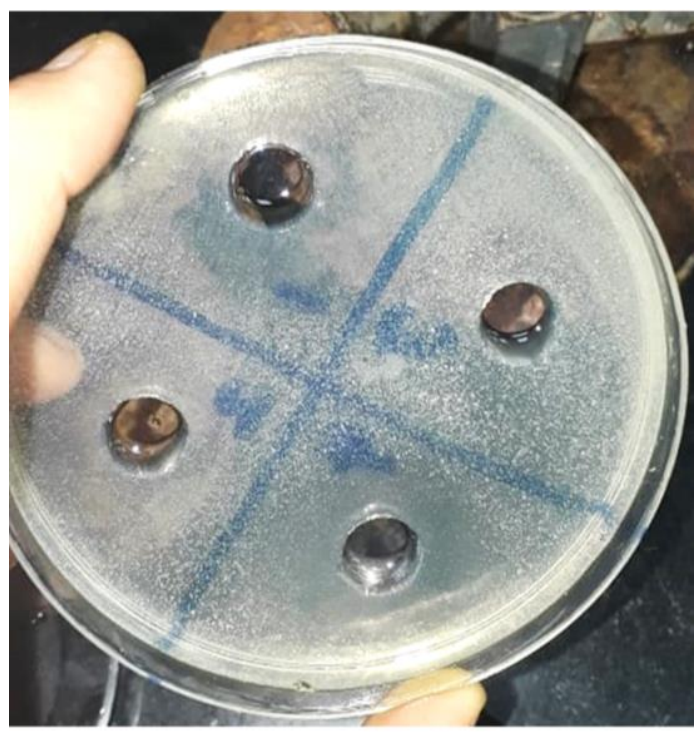

Fig. 1. Agar well diffusion technique for he CFS of $B$. subtilis A3 showing IZ against C.albicans

\subsection{Isolate A3 identification}

Isolate A3 was spore-forming Gram-positive rods (Fig. 2). The attained nucleotide sequence of the 16S rRNA of the A3 isolate was $99.8 \%$ homologous to the 16S rRNA sequence of $B$. subtilis subsp. spizizenii strain NBRC 101239 (NCBI GenBank accession code, NR 112686.1) and was put in the Culture Collection Ain Shams University (strain number, CCASU 2021-4) which belongs to the WDCM.

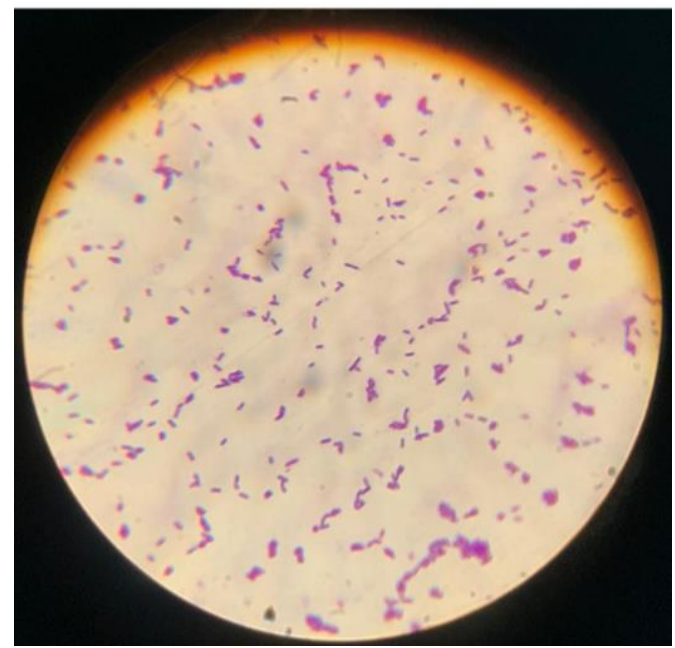

Fig. 2. Microscopical examination of B. subtilis A3 by Gram stain technique

\subsection{Time course of antifungal production in production media}

The highest production, represented by an IZ= $24 \mathrm{~mm}$, was attained after an incubation period of 3 days (Fig. 3). Consequently, the best incubation time for isolate A3 in ensuing trials was 3 days.

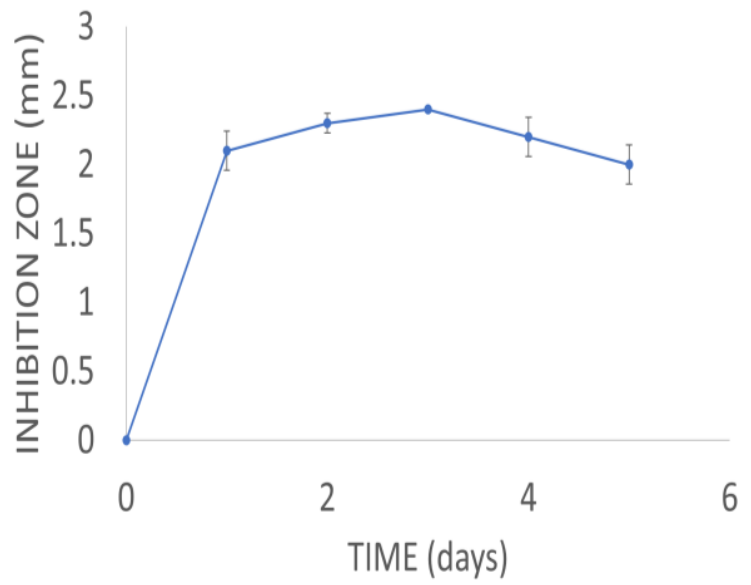

Fig. 3. Time course of antifungal production by B. subtilis isolate CCASU 2021-4 


\subsection{RSM for optimizing the antifungal activity}

The D-optimal design was undertaken to determine the best conditions for antifungal production by isolate A3. The tested variables, the runs, and the practical results for each experiment are presented in Table 2.

A fitted equation was proposed by the program using the results attained from the 13 runs as follows:

$\ln ($ Inhibition zone +0.27$)=-3.91782+0.048465 \mathrm{x}$ Temperature $+0.12944 \times \mathrm{pH}$

+2.67677E-007 $\mathrm{x}$ inoculum size - 3.22844E-009 $\mathrm{x}$ Temperature $\mathrm{x}$ inoculum size

The suitability of the model was determined using ANOVA and the P-value, which denotes the factors' significance on the metabolite(s) production (Table 3).

Table 3. ANOVA of the $D$ optimal design
The proposed model was found to be significant, as suggested by the F-value and $P$ value $(\mathrm{F}$ value $=16.22$ and $\mathrm{P}$-value $=0.001)$. The model terms $\mathrm{A}, \mathrm{C}, \mathrm{AC}$, and $\mathrm{C}^{2}$ are significant model terms since their P-value was less than 0.5. The coefficient of determination $\mathrm{R}^{2}$ suggested that $92 \%$ of changeability in response may well be clarified by our model. Furthermore, a good agreement was noticed among the predicted $\mathrm{R}^{2}$ (0.77) and the adjusted $R^{2}(0.86)$. Last of all, the adequate precision ratio, which was 9.82, confirmed an adequate signal. Therefore, our model was suitable to navigate the design space.

The three-dimensional (3D) response surface plots (Fig. 4), taken with the numerical optimization from the program, suggested the best conditions for greatest antifungal activity which were: a temperature of $30^{\circ} \mathrm{C}$, a $\mathrm{pH} 8$, and an inoculum size $5 \times 10^{7} \mathrm{cfu} / \mathrm{mL}$.

\begin{tabular}{llllll}
\hline Source & $\begin{array}{c}\text { Sum of } \\
\text { Squares }\end{array}$ & $\begin{array}{c}\text { Degrees of freedom } \\
(\mathbf{d f})\end{array}$ & Mean Square & F-Value & P-value \\
\hline Model & 58.77 & 5 & 11.75 & 16.22 & 0.0010 \\
A-Temperature & 5.34 & 1 & 5.34 & 7.37 & 0.0300 \\
B-PH & 0.11 & 1 & 0.11 & 0.15 & 0.7111 \\
C-inoculum size & 6.61 & 1 & 6.61 & 9.12 & 0.0194 \\
AC & 7.98 & 1 & 7.98 & 11.01 & 0.0128 \\
C 2 & 36.81 & 1 & 36.81 & 50.79 & 0.0002 \\
Residual & 5.07 & 7 & 0.72 & & \\
Lack of Fit & 5.07 & 6 & 0.85 & & \\
Pure Error & 0 & 1 & 0 & & \\
Cor Total & 63.84 & 12 & & & \\
\hline
\end{tabular}



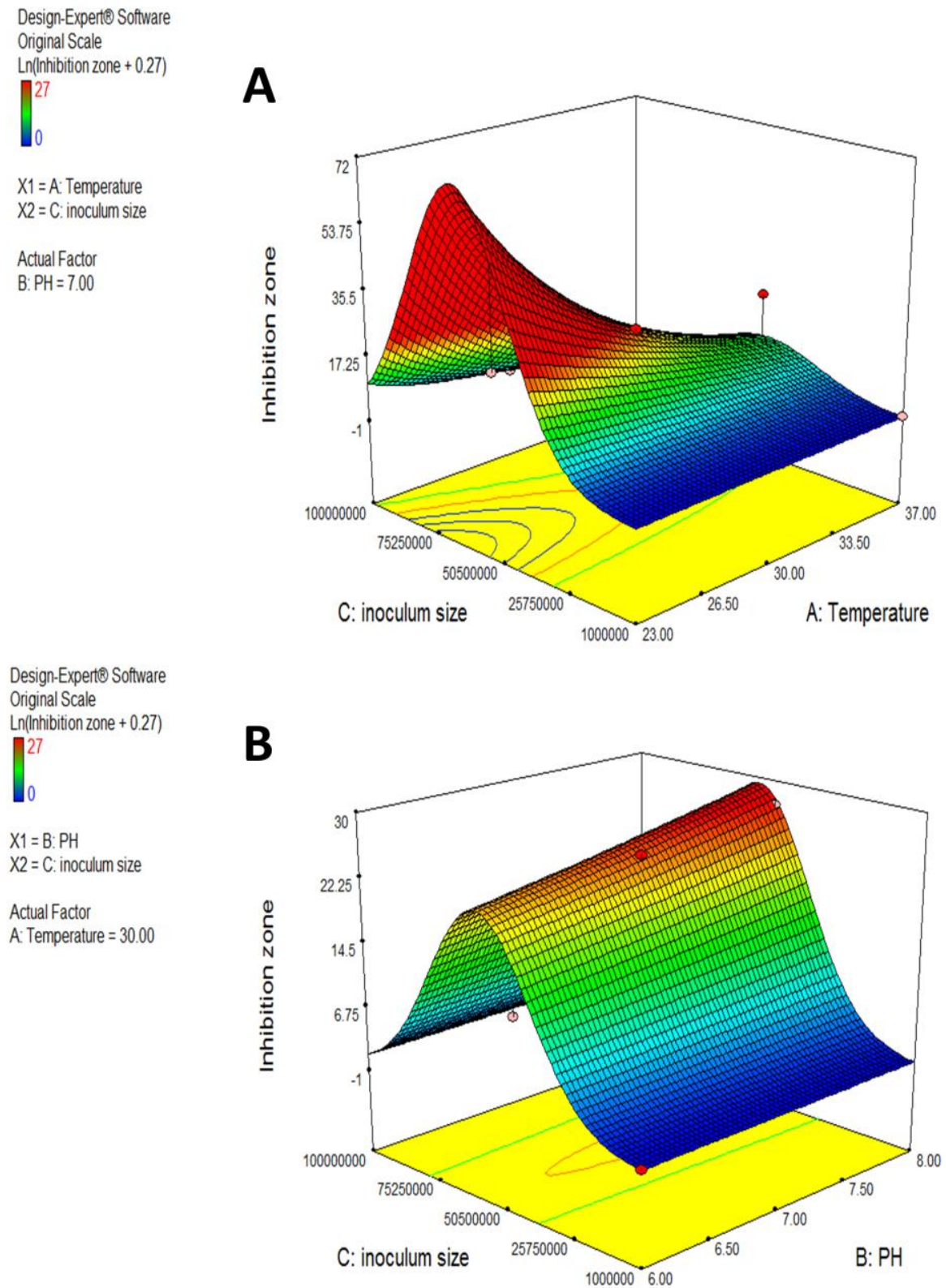

Fig. 4. 3D response surfaces representing the effect of the 3 parameters on the metabolite of A3 isolate. When the effect of two parameters was plotted, the remaining one was set at central level (A) inoculum size and temperature (B) $\mathrm{pH}$ and inoculum size

\subsection{Model diagnostics}

The normal probability plot of residuals (Fig. 5 A) suggested no signs of error verified by linear patterns.

The residuals versus Run number plot revealed that the points were distributed around zero (Fig. 5 B) indicating that our model fits the data.

The Box-Cox plot is useful in determining the most suitable power transformation. Here, the software recommended a transformation to the $\log$ and therefore this was carried out as shown in Fig. 5 C. 


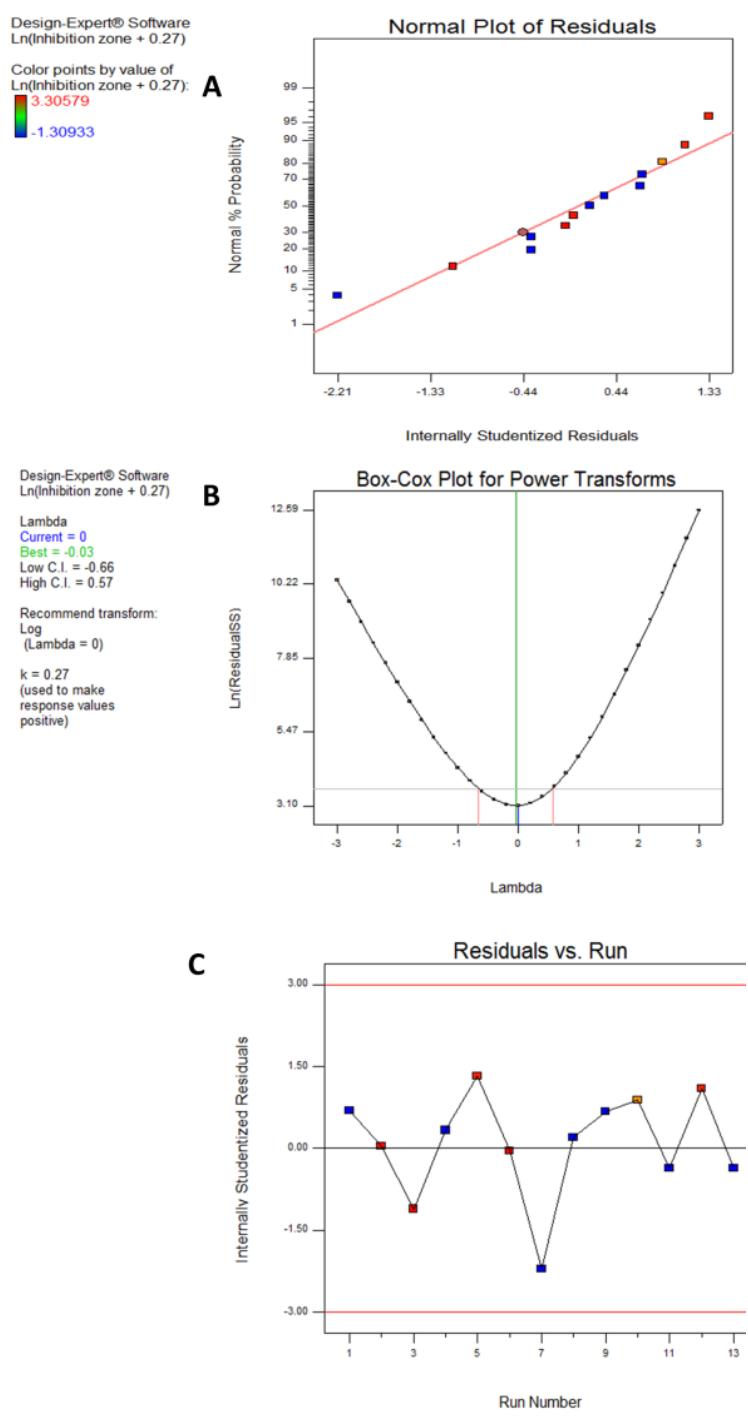

Fig. 5. Model diagnostic plots (A) The normal probability plot of residuals, (B) Box Cox plot, (C) Residuals versus Run number plot

\subsection{Validation experiment}

An IZ of $27 \mathrm{~mm}$ was attained for B. subtilis isolate CCASU 2021-4 by using the proposed best levels of the conditions tested. This result was very near to that estimated by the model (27.5 $\mathrm{mm})$, demonstrating an effective model. This IZ corresponded to a concentration of $1,360.82 \mu \mathrm{g} / \mathrm{mL}$ of the antifungal metabolite(s). Explicitly, optimization resulted in a 1.2-fold rise in antifungal production by the $B$. subtilis isolate CCASU 2021-4 when compared to yield using the unoptimized conditions $(1124.13 \mu \mathrm{g} / \mathrm{mL})$.

\section{DISCUSSION}

Invasive, deadly fungal infections, especially in immunodeficient patients are a critical reason for human morbidity and mortality [24]. The presently offered antifungals have numerous adverse effects which lessen their usage and safety profile. So searching for antifungal agents from natural sources is a necessity. In this study, a total of 10 soil samples were obtained from diverse areas in Cairo and were screened for the isolation of bacterial strains having antagonistic activity against the clinically relevant human fungal pathogen, C. albicans. Isolate A3, which depicted maximum antifungal activity, was Gram-positive and was identified as B. subtilis isolate CCASU 2021-4 (NCBI GenBank accession code, NR 112686.1).

B. subtilis is categorized into three subspecies: Bacillus subtilis subsp. subtilis, B. subtilis subsp. spizizenii and $B$. subtilis subsp. inaquosorum based on multi-gene phylogeny [25]. Recent studies suggested that $B$. subtilis subsp. spizizenii and B. subtilis subsp. inaquosorum should be upgraded to species status [26, 27]. Dunlap et al [28] recently reported that B. subtilis subsp. spizizenii only makes 1 lipopeptide called mycosubtilin, a finding which supports their upgrade to species-level status. These cyclic heptapeptides are present in several Bacillus strains used as biological control agents against fungal plant pathogens. They create pores in the fungal cell membrane causing loss of cell contents and death at certain concentrations [28].

Bacillus isolates are popular for producing a huge collection of antimicrobial structures, including lipopeptides like iturin, surfactin, fencing, and bacteriocins. For example, $B$. subtilis SCB-1 was found to be effective against various plant fungal pathogens including the genera Saccharicola [29]. In another study, 3 
lipopeptides from B. subtilis were described to be effective against Venturia inaequalis, fungi causing apple scab [30]. Zhang et al also proved the efficacy of volatile oil compounds produced by Bacillus strain ZD01, against A. solani, a fungal pathogen causing diseases of potato [31]. Moreover, B. subtilis subsp. inaquosorum was reported to produce, bacillomycin $\mathrm{F}$ and fengycin, 2 antifungal lipopeptides [32]. In 2018, Priyanka proved that the mycelial growth of $A$. alternata, which causes crop disease, was inhibited by B. subtilis subsp. spizizenii in vitro [33]. A recent study also showed that $B$. subtilis subsp. spiziennii M24 got the highest efficacy against blue mold which causes apple disease due to the production of antifungal lipopeptides from iturin and fengycin families [34]. However, we describe for the first time an antifungal activity from B. subtilis subsp. spizizenii against the human pathogenic fungi $C$. albicans.

Microbial secondary metabolites production is a complex process impacted by even minor variations in the media or conditions. Hence, our study targeted achieving the best conditions for enhanced production of the antifungal metabolite(s) from the tested isolate. Carbon and nitrogen sources are vital components in the medium for bacterial growth and metabolite production [35]. The media optimized in our previous study was selected as production media for the efficient antifungal metabolite(s) production from the tested isolate [22]. Earlier studies showed an improved secondary metabolite production exploiting complex carbon sources like starch [36]. Ammonium chloride was also established to be the appropriate nitrogen source in former studies [36].

The traditional methods employed for optimizing fermentation conditions are sluggish, monotonous, and costly; also, they disregard the mutual interactions between diverse factors [37]. The statistical procedures, like RSM, are auspicious being quick, consistent, and lead to considerable savings in the number of experiments and therefore time, equipment, chemicals, and effort [38]. These statistical methods permit studying simultaneous effects of different environmental factors on antifungal metabolite production [23, 39, 40]. RSM has been powerfully used in former studies to enhance antifungal metabolite production by various bacteria [41].

RSM offers several types of designs, and Doptimal design, one of the most precise designs [42], has been employed by several researchers in optimization studies [43, 44]. A sum of 13 experiments was carried out to study the effects of 3 variables $(\mathrm{pH}$, temperature, and inoculum size). To examine the design significance, ANOVA, which gives a useful understanding of the various sources, was employed $[45,46]$. The achieved F-value, 16.22 demonstrated that the model established was significant (P-value= $0.001)$. The obtained $R^{2}$ value (0.92) mirrors a good correlation for the regression model [47]. The power of the model to expect a response can be stated by the predicted $\mathrm{R}^{2}$ which should not vary from adjusted $\mathrm{R}^{2}$ by more than 0.2 [45]. Thus, our data presented a reasonable agreement between the adjusted and predicted $\mathrm{R}^{2}$ values (0.86 and 0.77, respectively). The signal-to-noise ratio, expressed by the adequate precision was 9.82, demonstrating a pleasing model discernment being greater than 4 [48].

Additionally, each factor's significance was described by P-value. In our study, the model terms A (temperature), $\mathrm{C}(\mathrm{pH})$ were significant $(\mathrm{P}<0.05)$. The $\mathrm{AC}$ interaction was also significant as was shown by the $P$-value obtained $(\mathrm{P}<0.05)$ while the $\mathrm{AB}$ and $\mathrm{CB}$ interactions were not $(P>0.05)$. A significant interaction indicates that one factor's effect relies on the level of the other [49]. The response surface plots were also generated, which help to understand the 
interactions between factors and therefore, to identify their optimum levels. From the 3D plots and numerical optimization function, the suggested ideal conditions for best antifungal yield were pinpointed and tried practically. The best concentration produced by $B$. subtilis A3 was $1,360.82 \mu \mathrm{g} / \mathrm{mL}$ which corresponds to a $1.2-$ fold enhancement in production as compared to that produced by using the un-optimized conditions $(1124.13 \mu \mathrm{g} / \mathrm{mL})$. Finally, the model diagnostic plots also proved the reliability of the model created.

\section{Conclusion}

In this study, we report for the first time a promising antifungal activity from $B$. subtilis subsp. spizizenii against $C$. albicans. We tested the influence of several factors on this activity and pinpointed the ideal levels required for the highest production. D optimal design proved to be very efficient in determining the interaction between the variables and brought about a 1.2fold rise in yield. Therefore, these findings may function as baseline data to elucidate the metabolites' nature and for scaling up its production by the respective isolate.

\section{Declarations}

\section{Ethics approval and consent to participate}

not applicable

\section{Consent to publish}

not applicable

\section{Availability of data and materials}

All are included in the main manuscript

\section{Competing interests}

Authors declare no competing interests

\section{Funding Statement}

No funding source was received

\section{Authors' contributions}

All authors participated in the practical work. The design of the work and analysis was carried out by GSH. All authors read and approved the final manuscript.

\section{Acknowledgments}

We hereby acknowledge the department of microbiology and Immunology, Faculty of Pharmacy, Ain Shams University for providing us with all facilities and support required to perform the practical work. We would like to thank Prof. Dr. Mahmood Yassein, Professor of Microbiology and Immunology, for kindly providing the standard C. albicans ATCC 10231.

\section{REFERENCES}

1. Buil JB, Meijer EFJ, Denning DW, Verweij PE, Meis JF. Burden of serious fungal infections in the Netherlands. Mycoses. 2020; 63(6): 62531.10.1111/myc.13089

2. Stohs E, Zimmer A. An Approach to Suspected Invasive Fungal Infection in Patients with Hematologic Malignancy and HCT Recipients with Persistent Neutropenic Fever Despite MoldActive Prophylaxis. Current Fungal Infection Reports. 2020; 14(1): 89-98.10.1007/s12281-02000375-6

3. Lamoth F, Lockhart SR, Berkow EL, Calandra T. Changes in the epidemiological landscape of invasive candidiasis. Journal of Antimicrobial Chemotherapy. 2018; 73(suppl_1):i4i13.10.1093/jac/dkx444

4. Quindós G, Gil-Alonso S, Marcos-Arias C, Sevillano E, Mateo E, Jauregizar $\mathrm{N}$, et al. Therapeutic tools for oral candidiasis: Current and new antifungal drugs. Medicina oral, patologia oral y cirugia bucal. 2019; 24(2): e172e80.10.4317/medoral.22978

5. Andes DR, Safdar N, Baddley JW, Playford G, Reboli AC, Rex JH, et al. Impact of Treatment Strategy on Outcomes in Patients with Candidemia and Other Forms of Invasive Candidiasis: A Patient-Level Quantitative Review of Randomized Trials. Clinical Infectious Diseases. 2012; 54(8): 


\section{$1110-22.10 .1093 / \mathrm{cid} / \mathrm{cis} 021$}

6. Barbosa F, Pinto E, Kijjoa A, Pinto M, Sousa E. Targeting antimicrobial drug resistance with marine natural products. International Journal of Antimicrobial Agents. 2020; 56(1): 106005.https://doi.org/10.1016/j.ijantimicag.2020. 106005

7. Alves R, Barata-Antunes C, Casal M, Brown AJP, Van Dijck P, Paiva S. Adapting to survive: How Candida overcomes host-imposed constraints during human colonization. PLOS Pathogens. 2020; $16(5)$ : e1008478.10.1371/journal.ppat.1008478

8. Li S, Wu F. Diversity and Co-occurrence Patterns of Soil Bacterial and Fungal Communities in Seven Intercropping Systems. Frontiers in Microbiology. 2018; 9(1521).10.3389/fmicb.2018.01521

9. Coleman JJ, Ghosh S, Okoli I, Mylonakis E. Antifungal activity of microbial secondary metabolites. PloS one. 2011; 6(9): e25321e.10.1371/journal.pone.0025321

10. Donovick R, Gold W, Pagano JF, Stout HA. Amphotericins $\mathrm{A}$ and $\mathrm{B}$, antifungal antibiotics produced by a streptomycete. I. In vitro studies. Antibiotics annual. 1955; 3: 579-86

11. Kerr JR. Bacterial inhibition of fungal growth and pathogenicity. Microbial Ecology in Health and Disease. 1999 ; $11(3)$ : 129 42.10.1080/089106099435709

12. Ryley JF, Wilson RG, Gravestock MB, Poyser JP. Experimental Approaches to Antifungal Chemotherapy. In: Garattini S, Goldin A, Hawking F, Kopin IJ, Schnitzer RJ, editors. Advances in Pharmacology. 18: Academic Press; 1981. p. 49176.

13. Földes T, Bánhegyi I, Herpai Z, Varga L, Szigeti J. Isolation of Bacillus strains from the rhizosphere of cereals and in vitro screening for antagonism against phytopathogenic, foodborne pathogenic and spoilage micro-organisms. Journal of Applied Microbiology. 2000; 89(5): 8406.https://doi.org/10.1046/j.1365-

2672.2000.01184.x
14. Russo F, Cabrita M, Feio S, Moiteiro C, Tavares R, Curto M, et al. Antifungal Activity of Bacillus Species and Pseudomonas aeruginosa Against Filamentous Fungi and Yeasts. 2002. p. 249-53.

15. Chan WC, Bycroft BW, Leyland ML, Lian LY, Roberts GC. A novel post-translational modification of the peptide antibiotic subtilin: isolation and characterization of a natural variant from Bacillus subtilis A.T.C.C. 6633. The Biochemical journal. 1993; 291 ( Pt 1)(Pt 1):237.10.1042/bj2910023

16. Milad M. Antagonistic activity of some bacterial species against other microorganisms isolated from the soil 2020.

17. Peela S, Kurada VB, Terli R. Studies on antagonistic marine actinomycetes from the Bay of Bengal. World journal of microbiology and biotechnology. 2005; 21(4): 5835.10.1007/s11274-004-3493-5

18. Hossain N, Rahman M. Antagonistic activity of antibiotic-producing Streptomyces $s p$. against fish and human pathogenic bacteria. Brazilian Archives of Biology and Technology. 2014; 57(2): 2337.10.1590/S1516-89132014000200011

19. Magaldi S, Mata-Essayag S, Hartung de Capriles C, Perez C, Colella MT, Olaizola C, et al. Well diffusion for antifungal susceptibility testing. International Journal of Infectious Diseases. 2004; 8(1): 39-45.10.1016/j.ijid.2003.03.002

20. Bundale S, Begde D, Nashikkar N, Kadam T, Upadhyay A. Isolation of aromatic polyketide producing soil Streptomyces using combinatorial screening strategies. OALib J. 2014;1:116.10.4236/oalib.preprints. 1200010

21. Morgan MC, Boyette M, Goforth C, Sperry KV, Greene SR. Comparison of the Biolog OmniLog Identification System and $16 \mathrm{~S}$ ribosomal RNA gene sequencing for accuracy in identification of atypical bacteria of clinical origin. J Microbiol Methods. 2009; 79(3): 336-43.S01677012(09)00315-7 [pii]

10.1016/j.mimet.2009.10.005 [doi]

22. El-Sayed SE, El-Housseiny GS, Abdelaziz NA, El-Ansary MR, Aboshanab KM. Optimized 
Production of the Allylamine Antifungal "Terbinafine" by Lysinibacillus Isolate MK212927 Using Response Surface Methodology. Infection and drug resistance. 2020; 13: 361326.10.2147/IDR.S267590

23. Singh RK, Kumar DP, Solanki MK, Singh P, Srivastva AK, Kumar S, et al. Optimization of media components for chitinase production by chickpea rhizosphere associated Lysinibacillus fusiformis B-CM18. J Basic Microbiol. 2013; 53(5): 451-60.10.1002/jobm.201100590

24. Roemer T, Krysan DJ. Antifungal drug development: challenges, unmet clinical needs, and new approaches. Cold Spring Harbor perspectives in medicine. 2014; 4(5): a019703

25. Yi H, Chun J, Cha C-J. Genomic insights into the taxonomic status of the three subspecies of Bacillus subtilis. Systematic and applied microbiology. 2013; 37(2): 95-9

26. Brito PH, Chevreux B, Serra C, Schyns G, Henriques A, Pereira-Leal J. Genetic Competence Drives Genome Diversity in Bacillus subtilis. Genome biology and evolution. 2017; 10.10.1093/gbe/evx270

27. Rooney AP, Price NPJ, Ehrhardt C, Swezey JL, Bannan JD. Phylogeny and molecular taxonomy of the Bacillus subtilis species complex and description of Bacillus subtilis subsp. inaquosorum subsp. nov. International Journal of Systematic and Evolutionary Microbiology. 2009; 59(10): 242936.https://doi.org/10.1099/ijs.0.009126-0

28. Dunlap CA, Bowman MJ, Rooney AP. Iturinic Lipopeptide Diversity in the Bacillus subtilis Species Group - Important Antifungals for Plant Disease Biocontrol Applications. Frontiers in Microbiology.

2019; 10(1794).10.3389/fmicb.2019.01794

29. Hazarika DJ, Goswami G, Gautom T, Parveen A, Das $\mathrm{P}$, Barooah $\mathrm{M}$, et al. Lipopeptide mediated biocontrol activity of endophytic Bacillus subtilis against fungal phytopathogens. BMC Microbiology. 2019; 19(1): 71.10.1186/s12866019-1440-8

30. Desmyttere H, Deweer C, Muchembled J, Sahmer
$\mathrm{K}$, Jacquin J, Coutte F, et al. Antifungal Activities of Bacillus subtilis Lipopeptides to Two Venturia inaequalis Strains Possessing Different Tebuconazole Sensitivity. Frontiers in microbiology. 2019; $\quad 10$ : 2327$.10 .3389 /$ fmicb.2019.02327

31. Zhang D, Yu S, Yang Y, Zhang J, Zhao D, Pan Y, et al. Antifungal Effects of Volatiles Produced by Bacillus subtilis Against Alternaria solani in Potato. Frontiers in Microbiology. 2020; 11(1196).10.3389/fmicb.2020.01196

32. Knight CA, Bowman MJ, Frederick L, Day A, Lee C, Dunlap CA. The first report of antifungal lipopeptide production by a Bacillus subtilis subsp. inaquosorum strain. Microbiological Research. 2018; 216: 406.https://doi.org/10.1016/j.micres.2018.08.001

33. Rajendran P, Sevugapperumal N, Pravin I, Moorthy A, Uthandi S. Antifungal activity of Bacillus subtilis subsp. spizizenii (MM19) for the management of Alternaria leaf blight of marigold. Journal of Biological Control. 2018; 32: 95102.10.18311/jbc/2018/21134

34. López-González RC, Juárez-Campusano YS, Rodríguez-Chávez JL, Delgado-Lamas G, Medrano SMA, Martínez-Peniche RÁ, et al. Antagonistic Activity of Bacteria Isolated from Apple in Different Fruit Development Stages against Blue Mold Caused by Penicillium expansum. The plant pathology journal. 2021; 37(1): 24-35.10.5423/PPJ.OA.07.2020.0121

35. Sa-Uth C, Rattanasena P, Chandrapatya A, Bussaman P. Modification of Medium Composition for Enhancing the Production of Antifungal Activity from Xenorhabdus stockiae PB09 by Using Response Surface Methodology. Int J Microbiol. 2018; 2018: $3965851.10 .1155 / 2018 / 3965851$

36. Fukuda T, Matsumoto A, Takahashi Y, Tomoda $\mathrm{H}$, Ōmura S. Phenatic acids A and B, new potentiators of antifungal miconazole activity produced by Streptomyces sp. K03-0132. The Journal of antibiotics. 2005; 58(4): 252.10.1038/ja.2005.29 
37. Li M, Penner G, Hernandez-Sanabria E, Oba M, Guan L. Effects of sampling location and time, and host animal on assessment of bacterial diversity and fermentation parameters in the bovine rumen. Journal of Applied Microbiology. 2009; 107(6): 1924-34

38. Vaidya R, Macmil S, Vyas P, Chhatpar H. The novel method for isolating chitinolytic bacteria and its application in screening for hyperchitinase producing mutant of Alcaligenes xylosoxydans. Letters in applied microbiology. 2003; 36(3): 12934

39. Nawani N, Kapadnis B. Optimization of chitinase production using statistics-based experimental designs. Process Biochemistry. 2005; 40(2): 65160

40. Mechri S, Kriaa M, Berrouina MBE, Benmrad MO, Jaouadi NZ, Rekik H, et al. Optimized production and characterization of a detergentstable protease from Lysinibacillus fusiformis C250R. International journal of biological macromolecules. 2017; 101: 383-97

41. Souagui Y, Tritsch D, Grosdemange-Billiard C, Kecha M. Optimization of antifungal production by an alkaliphilic and halotolerant actinomycete, Streptomyces sp. SY-BS5, using response surface methodology. Journal de mycologie medicale. 2015; 25(2): 10815.10.1016/j.mycmed.2014.12.004

42. Xu W, Wong WK, Tan KC, Xu J. Finding HighDimensional D-Optimal Designs for Logistic Models via Differential Evolution. IEEE access: practical innovations, open solutions. 2019; 7: 7133-46.10.1109/ACCESS.2018.2890593

43. Nasrollahzadeh M, Ganji F, Taghizadeh S, Daraei B, Loboa E, Vasheghani-Farahani E. Development and Optimization of Cephalexin-Loaded Solid Lipid Nanoparticles Using D-optimal Design. Advanced Science, Engineering, and Medicine. 2016; 8: 695-704.10.1166/asem.2016.1917

44. El-Housseiny GS, Ibrahim AA, Yassien MA, Aboshanab KM. Production and statistical optimization of Paromomycin by Streptomyces rimosus NRRL 2455 in solid-state fermentation.
BMC microbiology. 2021; 21(1): 34$.10 .1186 / \mathrm{s} 12866-021-02093-6$

45. Mourabet M, El Rhilassi A, El Boujaady $\mathrm{H}$, Bennani-Ziatni M, Taitai A. Use of response surface methodology for optimization of fluoride adsorption in an aqueous solution by Brushite. Arabian Journal of Chemistry. 2017; 10: S3292S302.10.1016/j.arabjc.2013.12.028

46. Kasiri MB, Modirshahla N, Mansouri $H$ Decolorization of organic dye solution by ozonation; Optimization with response surface methodology. International Journal of Industrial Chemistry. 2013; 4(1): 3.10.1186/2228-5547-4-3

47. Chen X-C, Bai J-X, Cao J-M, Li Z-J, Xiong J, Zhang L, et al. Medium optimization for the production of cyclic adenosine 3', 5'monophosphate by Microbacterium sp. no. 205 using response surface methodology. Bioresource technology. 2009; 100(2): 91924.10.1016/j.biortech.2008.07.062

48. Abdel-Hafez SM, Hathout RM, Sammour OA. Towards better modeling of chitosan nanoparticle production: screening different factors and comparing two experimental designs. International journal of biological macromolecules. 2014; 64: 334-40.10.1016/j.ijbiomac.2013.11.041

49. Rajendran D, Venkatachalam P, Ramakrishnan J. Response Surface Methodology: Optimisation of Antifungal Bioemulsifier from Novel Bacillus thuringiensis. The Scientific World Journal. 2014; 2014: 423289.10.1155/2014/423289 